\title{
Low-salinity-based enhanced oil recovery literature review and associated screening criteria
}

\author{
Mukul Chavan $^{1} \cdot$ Abhijit Dandekar $^{1} \cdot$ Shirish Patil ${ }^{1} \cdot$ Santanu Khataniar ${ }^{1}$
}

Received: 16 October 2018 / Published online: 28 May 2019

(c) The Author(s) 2019

\begin{abstract}
A thorough literature review is conducted that pertains to low-salinity-based enhanced oil recovery (EOR). This is meant to be a comprehensive review of all the refereed published papers, conference papers, master's theses and other reports in this area. The review is specifically focused on establishing various relations/characteristics or "screening criteria" such as: (1) classification/grouping of clays that have shown or are amenable to low-salinity benefits; (2) clay types vs. range of residual oil saturations; (3) API gravity and down hole oil viscosity range that is amenable for low salinity; (4) salinity range for EOR benefits; (5) pore sizes, porosity, absolute permeability and wettability range for low-salinity EOR; (6) continuous low-salinity injection vs. slug-wise injection; (7) grouping of possible low-salinity mechanisms; (8) contradictions or similarities between laboratory experiments and field evidence; and (9) compositional variations in tested low-salinity waters. A proposed screening criterion for low-salinity waterflooding is introduced. It can be concluded that either one or more of these mechanisms, or a combination thereof, may be the case-specific mechanism, i.e., depending on the particular oil-brine-rock (OBR) system rather than something that is "universal" or universally applicable. Therefore, every OBR system that is unique or specific ought to be individually investigated to determine the benefits (if any) of low-salinity water injection; however, the proposed screening criteria may help in narrowing down some of the dominant responsible mechanisms. Although this review primarily focuses on sandstones, given the prominence of carbonates containing $60 \%$ of the world's oil reserves, a summary of possible mechanisms and screening criteria, pertaining to low-salinity waterflooding, for carbonates is also included. Finally, the enhancement of polymer flooding by using low-salinity water as a makeup water to further decrease the residual oil saturation is also discussed.
\end{abstract}

Keywords Low salinity $\cdot$ Waterflooding $\cdot$ EOR $\cdot$ Clays $\cdot$ Screening criteria $\cdot$ Mechanism

\section{Introduction}

Improvement in the recovery of oil by low or reduced salinity water was first reported by Bernard (1967). In 2004, Webb was the first to publish the results on a single-well test and provided field evidence of reduction in residual oil by low-salinity water (Webb et al. 2004). The interest in lowsalinity waterflooding is picked up again in the mid-nineties with many publications that appeared from Dr. Morrow's research group (University of Wyoming), primarily based

Edited by Yan-Hua Sun

Abhijit Dandekar

adandekar@alaska.edu

1 Department of Petroleum Engineering, University of Alaska Fairbanks, Fairbanks, AK, USA on laboratory corefloods. However, up until 2005 the interest in low-salinity waterflooding remained at a fairly low level. Between 2005 and 2010, the increase in low-salinity papers was exponential with 25 papers appearing in the literature in 2010, as reported by Morrow and Buckley (2011). According to Morrow and Buckley (2011), despite the growing interest in low salinity, a consistent mechanistic explanation had not yet emerged. This is still true in 2016. In part, this may be the result of variations in test procedures (especially rocks and crude oils). The complexity of the minerals, crude oils, and aqueous-phase compositions and the interactions among all these phases also may contribute to the lack of a universally applicable mechanism for the low-salinity effect. The variety of circumstances under which the low-salinity waterflood may or may not be successful suggests that more than one mechanism may be in play. 


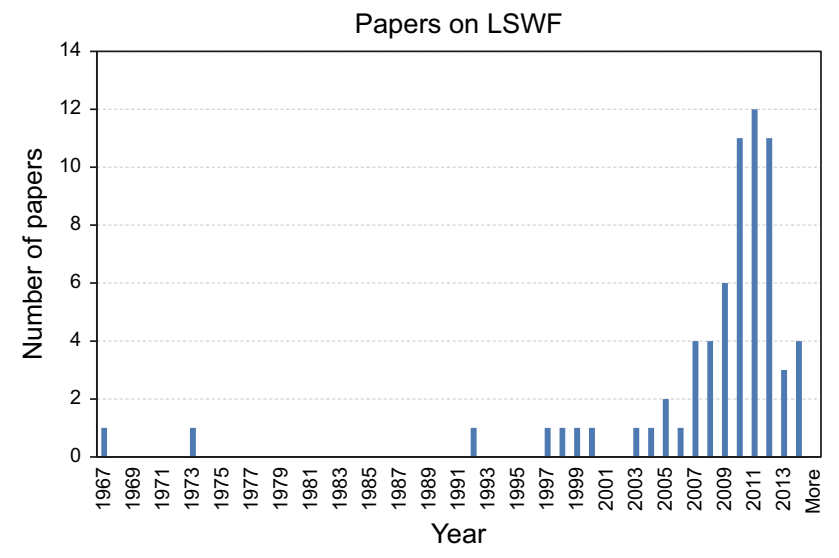

Fig. 1 SPE publications on LSWF

In order to better understand the effects of low-salinity waterflooding (LSWF) for Alaska's North Slope (ANS) reservoirs, this paper summarizes various literature and research conducted on this topic. Traditional waterflooding techniques are the oldest and most common methods to improve oil recovery beyond reservoir depletion. In contrast, LSWF is a relatively new enhanced oil recovery method in which injection water salinity is reduced to further improve oil recovery. Morrow and Buckley (2011) observed that interest in LSWF has increased in recent years as indicated by the number of publications and presentations with LSWF as their topic. A histogram similar to Morrow and Buckley's, as shown in Fig. 1, which includes only the Society of Petroleum Engineers (SPE) publications, indicates that authors continue to investigate LSWF. Table 1 shows a list of publications and indicates sources of information discussed in this paper. Data from the table indicate that clay type, wettability and water chemistry are the most discussed topics (see Fig. 2).

LSWF has been extensively studied, and many authors have documented the benefits on oil recovery, but there is no consensus regarding the governing mechanisms of this enhanced recovery technique. It is believed that certain conditions are necessary to observe the benefits of low-salinity injection, but no single mechanism has been accepted as being universally applicable. A greater part of the literature studied showed an increase in oil recovery by LSWF in laboratory coreflooding experiments. Benefits have also been realized in the field, including on ANS. Dang et al. (2013a) presented a review on the topic of LSWF in which the mechanism behind the LSWF in last two decades was discussed and also made a comparison of the laboratory and field studies.

This paper summarizes various mechanisms and reservoir properties that contribute to additional oil recovery by LSWF, as found through an extensive literature review.
Topics include clay types, oil properties such as API gravity and viscosity, injection water salinity ranges, pore size, porosity, permeability, wettability and compositional variation in low-salinity waters. The literature review concludes by discussing comparisons between laboratory and field studies and by providing screening criteria for LSWF.

\section{Classification/grouping of clays amenable to low-salinity benefits}

Many authors state that clay must be present in order to see benefits from LSWF, and studies have shown that LSWF is effective in various types of clays. To determine what types of clays benefit LSWF, it is necessary to understand the interactions between clay particles, water and oil. Most sandstone reservoirs are made up of a mixture of sand and clay particles and contain a mixture of water and oil in the pore space.

Although, Tchistiakov's paper from 2000 (Tchistiakov 2000) does not focus on low-salinity, the cation-clay interaction as it pertains to LSWF is included since clay is the third most discussed variable in the context of LSWF. According to Tchistiakov, only some cations are attached to the clay surface as an adsorbed layer, while others are free, forming a diffuse ionic layer some distance away from the clay surface. The concentration and distribution of these free cations is controlled by the balance between electrostatic attraction of the clay surface and thermal motion of the cations. Tchistiakov schematically illustrates the end of the diffuse ionic layer, which marks the beginning of the free solution region (concentration of anions = cations) by a rather sharp demarcation. According to Tchistiakov, the bonds between the cations and the clay surfaces are strengthened due to an increase in valence exchangeable cations, which reduces the potential and the diffuse layer thickness. In general, the clay stability in sandstone decreases with a decrease in the exchangeable cation charge and radius. Thus, clay surfaces release monovalent cations, which go to the diffuse layer around the clay particles.

The connection between oil and clays from a chemistry perspective is described by Lager et al. (2008a, b). The authors conclude that the oil molecules are held on the surface of the negatively charged clay particles mainly by divalent cations. These are positively charged ions, such as calcium $\left(\mathrm{Ca}^{2+}\right)$ or magnesium $\left(\mathrm{Mg}^{2+}\right)$, which act as tethers to hold the oil molecules onto the clay. When flooded with water that has a lower salinity than the reservoir formation water, free cations in the displacing fluid, for example monovalent sodium ions $\left(\mathrm{Na}^{+}\right)$, exchange with the divalent cations holding the oil in place and release the oil molecules, allowing these to be swept out of the rock pores. It has been observed that the more clay present in the reservoir, 
1346

Petroleum Science (2019) 16:1344-1360

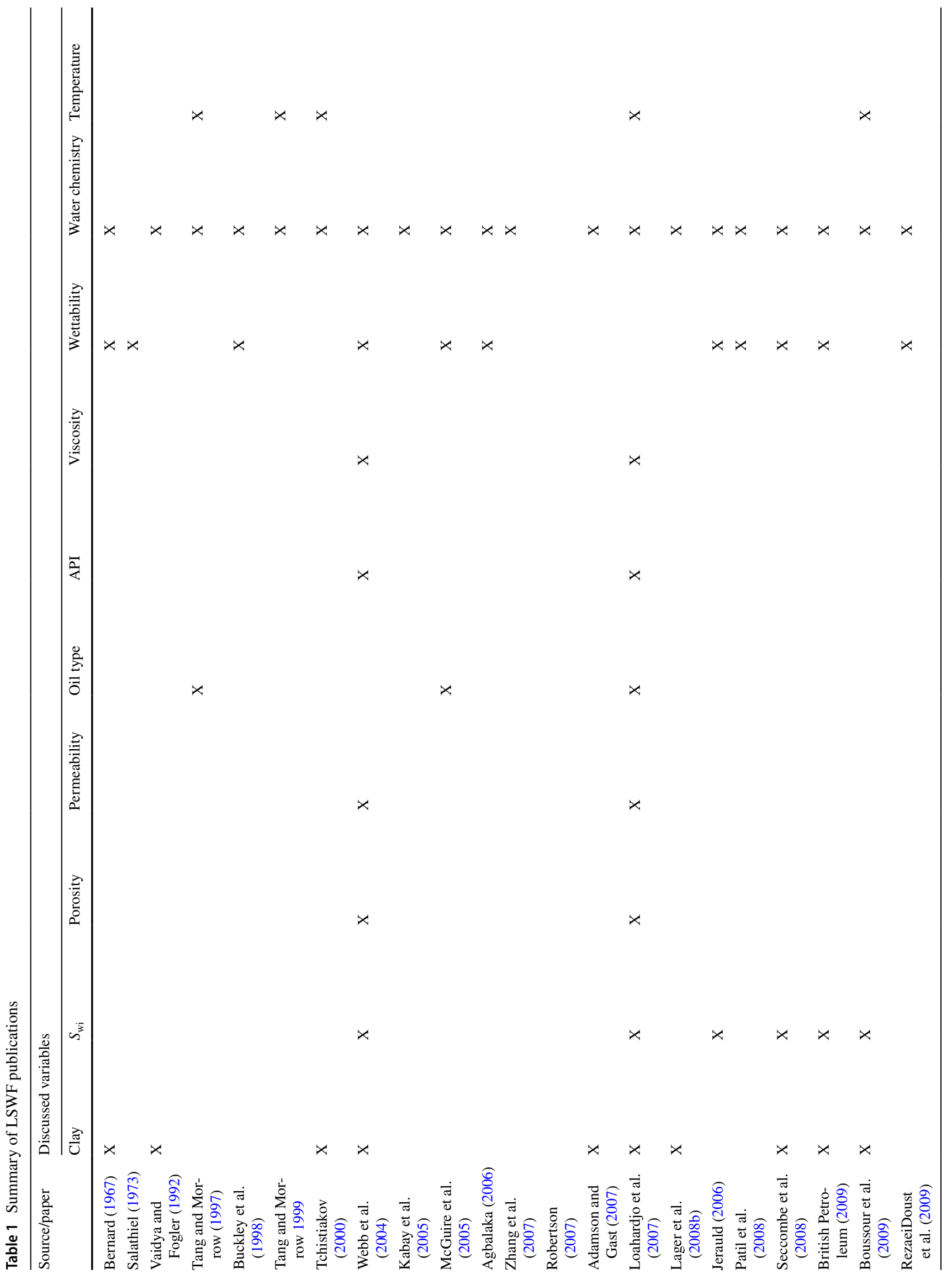

Springer 


$$
[
$$


1348

Petroleum Science (2019) 16:1344-1360

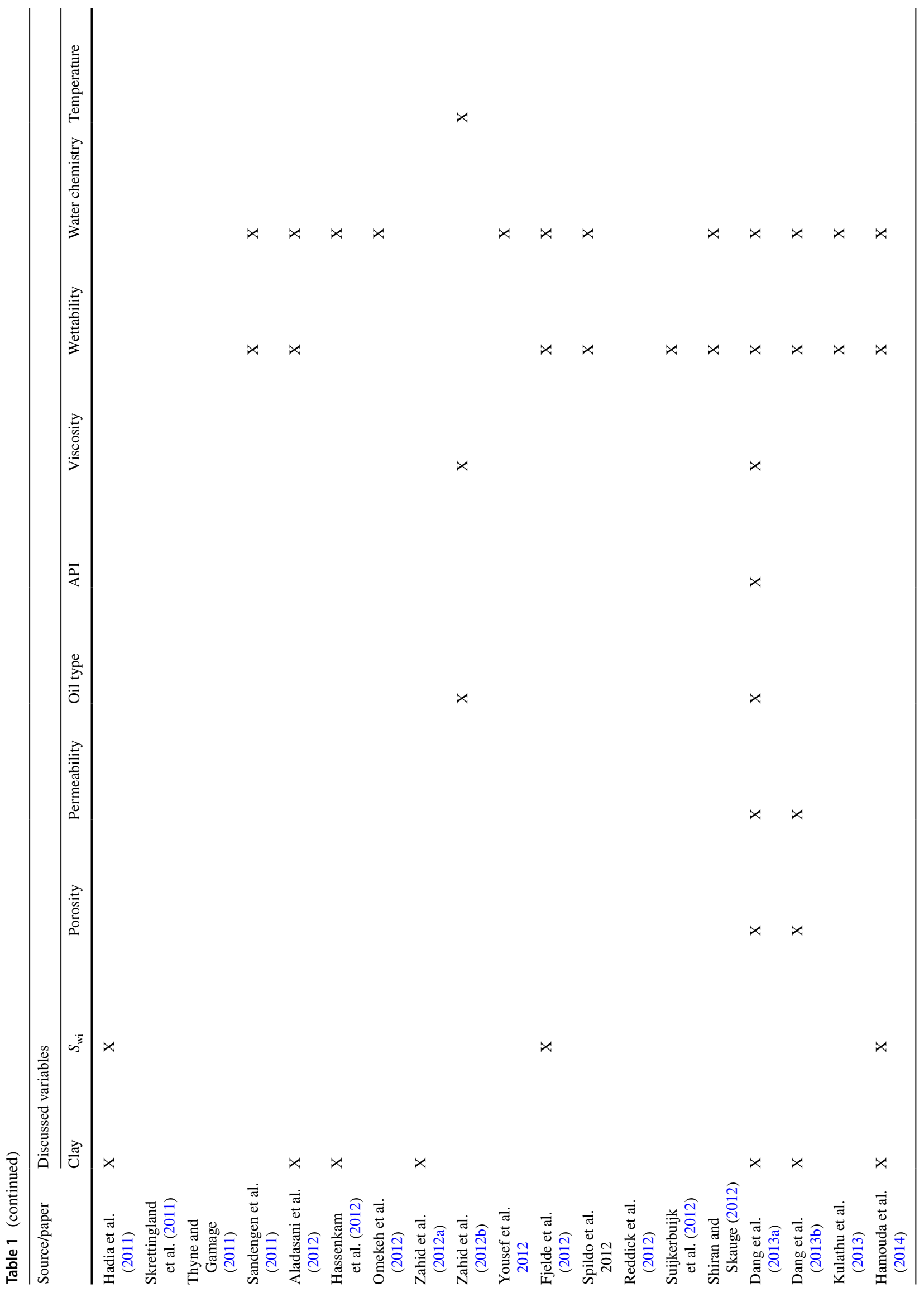

算 Springer 


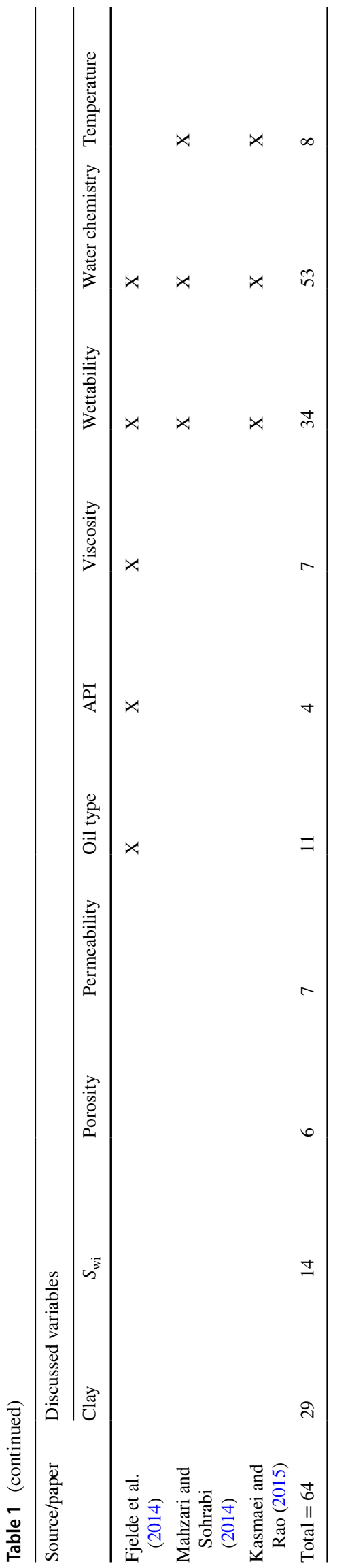

the greater will be the benefit of using low-salinity water (Jerauld et al. 2006). A basic schematic of this mechanism is shown in Fig. 3.

Lee et al. (2010) refers to the structural layers as an electric double layer, which consists of an inner adsorbed layer of positive ions (the adsorption layer), and an outer diffuse layer (the osmosis layer) consisting of mainly negative ions; a description somewhat similar to that of Tchistiakov (2000). The thickness of the double layer depends on the ion concentration in the surrounding water. In the case of high salinity water containing more ions, the double layer is more compact, and the oil release from the clay surface is inhibited. However, when low-salinity water is introduced, the double layer expands. The adsorption layer contains divalent calcium or magnesium ions, which act as tethers between the clay and oil droplets. Injecting reduced salinity water opens up the diffuse layer, enabling monovalent ions such as sodium, carried in the injected water, to penetrate into the double layer. Here, the monovalent ions displace the divalent ions, thereby freeing up the oil so that it can be produced from the reservoir.

Many of the research papers studied show that the presence of active clay minerals is necessary to obtain lowsalinity EOR effects. According to Austad et al. (2010), a negative charge on the clay surface is due to the role of clay minerals often characterized as cation exchange material, because of structural charge imbalance, either in the silica or in the aluminum layer and also at the edge surfaces. Tchistiakov described a generic clay-cation interaction, which is, however, dependent on the types of cations and the clays. Jerauld et al. (2006) state that rock mineralogy (an active clay being an integral component) impacts low-salinity flooding and thus suggest that this dependence should be included in simulating these types of floods. A table from the International Drilling Fluids technical manual that lists the cation exchange capacities (CEC) of the three prominent clay types, kaolinite, illite/mica and montmorillonite, is presented by Austad et al. (2010). The table shows that kaolinite has the lowest CEC, suggesting that kaolinite is the least favorable clay material for low-salinity flooding. Thus, the clays beneficial strictly from a CEC standpoint for lowsalinity water flooding can be ranked as kaolinite <illite/ mica $<$ montmorillonite. However, in contrast, some studies have been conducted where additional oil recovery was observed with kaolinite as the dominant clay material present (Jerauld et al. 2006; Seccombe et al. 2008; Hadia et al. 2011; Robertson et al. 2003). Jerauld et al. (2006) also presented laboratory and single-well chemical tracer test data that correlated quite well. These data showed that the incremental oil recovery was directly proportional to the kaolinite clay content. 


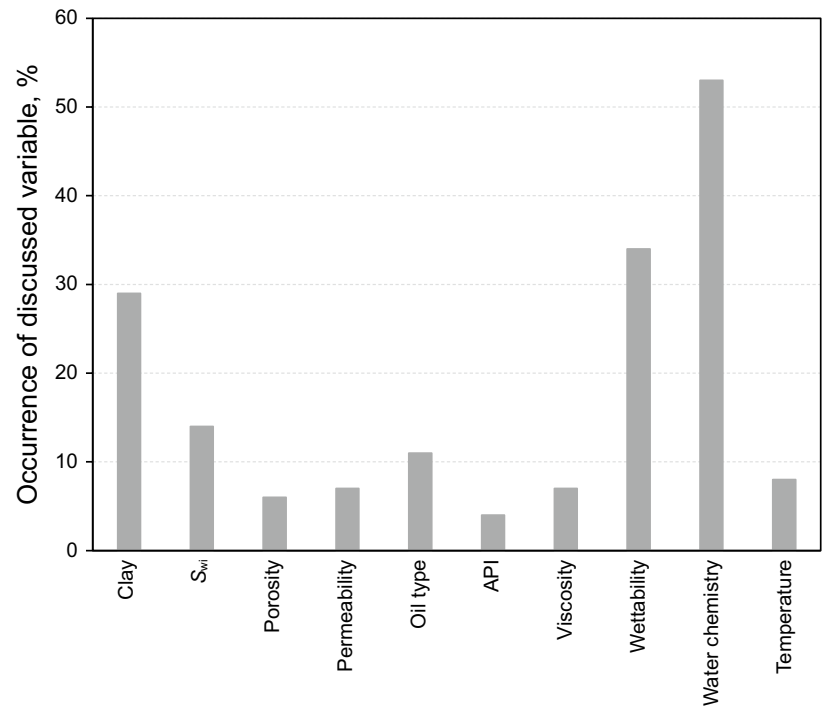

Fig. 2 Occurrence of discussed variables in LSWF tests reported in the reviewed literature

\section{Clay types vs. range of residual oil saturations}

According to a clay classification table presented by Tchistiakov (2000), the three main classes of clays are (1) discretely dispersed particle clays, (2) pore-lining clays and (3) pore-bridging clays. Kaolinite predominantly falls in the first class while illite, chlorite and montmorillonite fall in the second and third classes. By definition, the first class of clays can contribute to fines migration. Similarly, as the name suggests, pore-lining clays are attached to pore walls and form continuous thin films while the pore-bridging clays can potentially block or bridge the pore space.

The presence of clays as some type of precondition to benefit from LSWF is agreed upon by many authors; however, there appears to be a lack of systematic study or a correlation on clay type versus residual oil saturation. Robertson et al. (2003) state that the effect of brine composition on oil recovery is mainly influenced by the rock (presence and distribution of kaolinite is important) and the crude oil characteristics. Based on their core flooding studies, Robertson et al. (2003) hypothesize that kaolinite plays a key role in the recovery mechanism of LSWF, which is due to the mobility of kaolinite (see previous paragraph). Seccombe et al. (2008) also graphically presented a straight-line correlation between additional recovery due to LoSal ${ }^{\mathrm{TM}}$ vs. kaolinite concentration for the Endicott field in Alaska, which indicates that the additional recovery ( $\%$ pore volume) is $\sim 1.1$ times the kaolinite concentration. The data used in developing this specific correlation include core flood as well as reservoir data. The additional oil recovery in cases of 500-1000 mD Berea sandstone cores was attributed to the presence of kaolinite in the cores by other authors as well (Morrow and Buckley 2011).
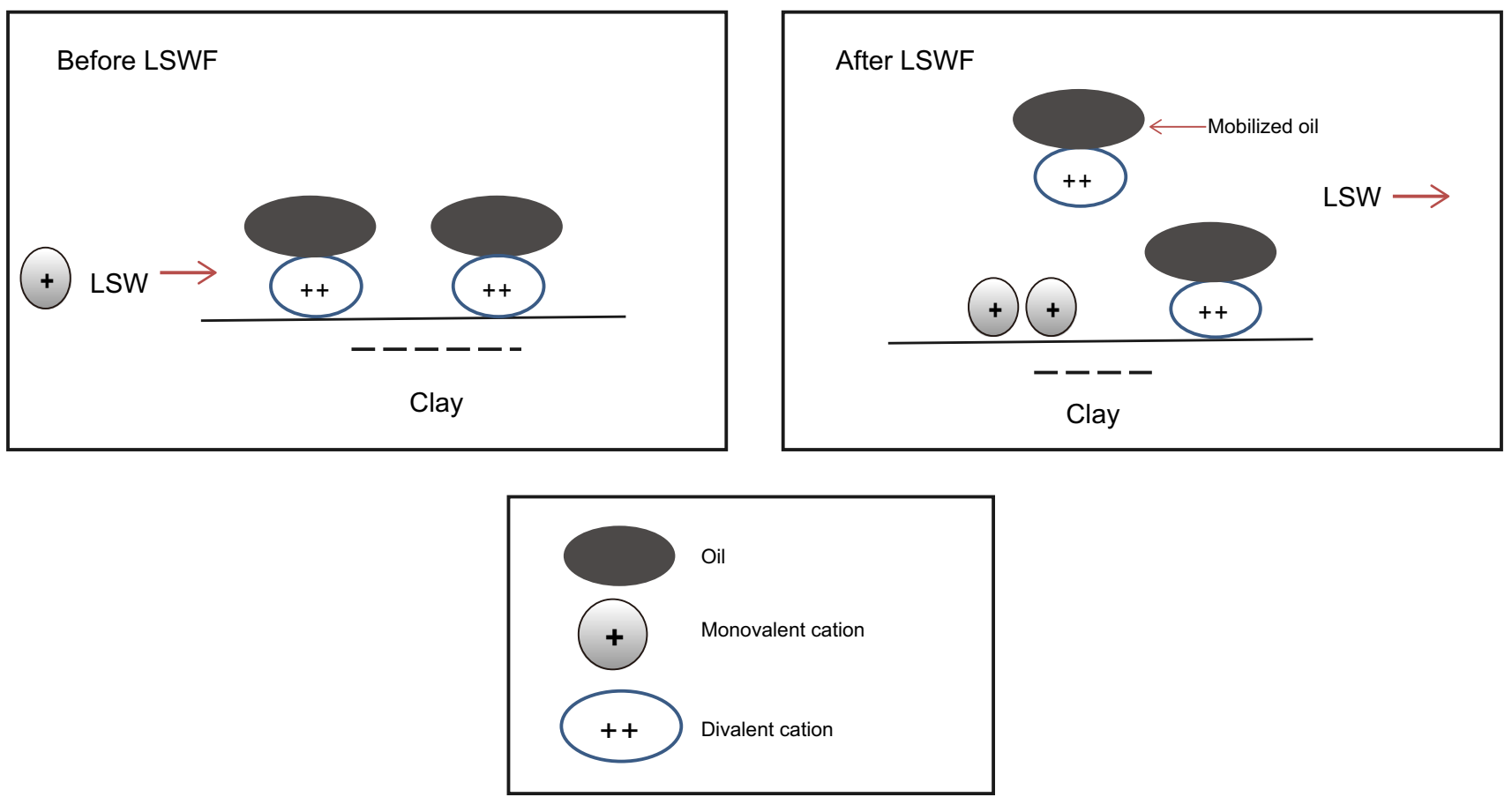

Fig. 3 A basic schematic portraying the mechanism of Lager et al. (2008a, b) 
However, the reviewed literature also reports LSWF benefits for sandstone core material containing other types of clays such as illite, mica, muscovite chlorite but no kaolinite (Boussour et al. 2009; Cissokho et al. 2010). Note though that the (positive) response to LSWF in kaolinite free cores is somewhat delayed in comparison with those containing kaolinite. These observations lead Boussour et al. (2009) to conclude that the presence of kaolinite is not a necessary condition for increasing oil recovery by LSWF.

Benefits from LSWF are also reported for clay-free carbonate reservoirs (observations based on core floods, Zahid et al. 2012a, b; and core floods as well as a pilot, Yousef et al. 2012). However, note that the authors use a term called as "smart water" rather than low salinity, primarily targeting the dilution of seawater and ascribe the benefits to wettability alteration toward water wetness. Although, low-salinity water is known by various terms such as "designer water," "advanced ion managed water" and "smart water (commonly used in the context of carbonates)," broadly speaking, from a total salinity standpoint they essentially mean the same thing; however, subtle differences do exist, in that the salinity may be the same but the divalents are removed or minimized.

\section{API gravity and down hole oil viscosity range that is amenable for low salinity}

There is little evidence relating oil API gravity and oil viscosity to LSWF; rather these two physical properties appear to be a given parameter in a certain study. The existing data are a result of reported oil properties used in experiments, not from studies that specifically relate oil properties to LSWF benefits. Some oil property data used in LSWF experiments are presented in Table 2. There are wide ranges of API gravity and viscosity for the oils used in LSWF experiments where additional oil recovery was observed, thus indicating that these properties may not play any significant role in LSWF.

A direct correlation of the physical properties of the oil to the benefits from LSWF may not be feasible; however, they can certainly be indirectly linked through the composition of the oil, which influences both the physical properties of the oil and the incremental oil recovery. The influence of oil composition on incremental oil recovery is derived through the presence of polar compounds in the oil, which has been reported by several authors, Austad et al. (2010), Ashraf et al. (2010), Fjelde et al. (2012, 2014), Tang and Morrow (1997, 1999), Lager et al. (2008a, b). Thus, the oil type from a compositional rather than physical properties standpoint is important for achieving the benefits of LSWF. No benefits are seen in cases of refined or synthetic oils that obviously do not contain any polar molecules (Austad et al. 2010).
According to Fjelde et al. (2012, 2014), polar components from the oil are bonded to clay surfaces by divalent cations making the system somewhat oil-wet, which is then altered by the LSWF to a more favorable wetting state that increases the oil recovery.

\section{Salinity range for EOR benefits}

It is quite obvious that, anecdotally, the reviewed literature suggests that the oil recovery increases by decreasing the salinity of injected water; however, the optimum injected water salinity depends on the actual composition of the reservoir brine. Vaidya and Fogler (1992) conclude that formation permeability is negatively impacted due to ionic conditions of low salinity and high $\mathrm{pH}$ causing fines migration and drastic damage. Similarly, Sorbie and Collins (2010) basically state that a high salinity brine (together with clayey rock and a crude oil, i.e., containing polar components) is correct conditions for the LSWF effect to be observed. The transition to a mixed-wet condition when LSW is injected is believed to be the mechanism responsible for this behavior. Also, the efficiency of LSWF is related to initial water saturation and hence formation brine must be present in the reservoir (Jerauld et al. 2006; Austad et al. 2010).

The usual salinity for LSWF effects is between 1000 and 2000 ppm (Austad et al. 2010); however, salinities from 3000 ppm (Webb et al. 2004) to 5000 ppm (McGuire et al. 2005) showing positive effects are also reported. Therefore, considering the data presented in Table 2 and the aforementioned references, the upper limit of optimum salinity appears to be $5000 \mathrm{ppm}$. This is supported by the fact that a single-well chemical tracer test (SWCTT) in the Ivishak reservoir, with 7000 ppm salinity, showed no improvement in oil recovery (McGuire et al. 2005). Additionally, Morrow and Buckley (2011) categorize the low-salinity range as follows, up to $5000 \mathrm{ppm}$ in laboratory tests, and 2000-3000 ppm in field tests.

\section{Porosity, pore sizes, absolute permeability and wettability range for low-salinity EOR}

Other perceived factors that may influence LSWF include porosity, pore sizes, absolute permeability and wettability. The literature review produced little evidence directly correlating porosity, pore size and permeability to LSWF. Similar to the oil properties mentioned above (API gravity and viscosity), these properties are simply reported as part of the experiments, but there have been no sensitivity studies conducted to determine their effect on LSWF, again indicating that these properties may not be playing any specific roles in LSWF. Some of these properties are listed in Table 2. On the 
Table 2 Rock and fluid properties from various LSWF tests

\begin{tabular}{|c|c|c|c|c|c|c|c|}
\hline Source/paper & $\begin{array}{l}\text { Incremental oil } \\
\text { recovery, \% }\end{array}$ & Porosity, $\%$ & Permeability, mD & API gravity & Viscosity, cP & $\begin{array}{l}\text { Optimum salin- } \\
\text { ity (TDS), ppm }\end{array}$ & $\mathrm{pH}$ \\
\hline Tang and Morrow (1997) & NR & 23 & $487-614$ & NR & $0.52-1.05$ & 3000 & $6.9-7.3$ \\
\hline Webb et al. (2004) & $25-50$ & $20-30$ & $200-700$ & $33-12$ & $0.45-50$ & 3000 & 7.1 \\
\hline McGuire et al. (2005) & 13 & $16-24$ & NR & NR & NR & 1500 & $>9$ \\
\hline Zhang et al. (2007) & 7 & $17-24$ & $60-1100$ & $23-25$ & $8-58$ & NR & $>9$ \\
\hline Loahardjo et al. (2007) & $16-29$ & $20-27$ & $400-800$ & 25 & $56-112$ & 3500 & 7 \\
\hline Lager et al. $(2008 \mathrm{a}, \mathrm{b})$ & 10 & NR & NR & NR & NR & 2600 & 10.5 \\
\hline Patil et al. (2008) & 14 & 19 & 65 & NR & NR & 5500 & NR \\
\hline Pu et al. (2010) & NR & $10-20$ & $0.25-250$ & $24-31$ & $20-50$ & 3000 & NR \\
\hline Robertson (2010) & NR & $19-21$ & $90-130$ & NR & NR & 3300 & NR \\
\hline Vledder et al. (2010) & $10-15$ & NR & NR & NR & NR & 2200 & NR \\
\hline Cissokho et al. (2010) & 10 & $16-20$ & $400-800$ & 37 & 5.42 & 1000 & $>7$ \\
\hline Hadia et al. (2011) & 8 & $16-22$ & $10-4800$ & 39 & 5.96 & 4300 & NR \\
\hline Fjelde et al. (2012) & NR & $27-28$ & $70-170$ & NR & 1.5 & 2000 & $>7$ \\
\hline
\end{tabular}

$* N R$ not reported

other hand, wettability, and its relation to LSWF, has been studied in great detail.

The role of wettability in LSWF has been alluded to earlier, and there appears to be agreement among many researchers (Rivet et al. 2010; Sorbie and Collins 2010; Vledder et al. 2010; Skrettingland et al. 2011; Hadia et al. 2011; Shiran and Skauge 2012) that the wetting state of a reservoir affects recovery of oil by LSWF. In general, three different fluid property parameters, namely $\mathrm{pH}$, salinity of the injected water, and the polar components in the crude oil and their interaction with the reservoir rock are considered as influential as far as wettability alteration and thus its impact on LSWF is concerned. This has been variously described by several authors (Berg et al. 2009; Buckley et al. 1998; Tang and Morrow 1997).

Agbalaka (2006) and Kulathu et al. (2013) conducted experiments to observe the change in residual oil saturation in a core after low-salinity waterflooding and found that low-salinity waterflooding causes the more oil-wet rock to become water-wet. Similar observation was also made by Rivet et al. (2010), who stated that the injection of LSW causes "persistent" wettability to change toward waterwet. This change from oil-wet to water-wet corresponds to decreasing residual oil saturation and thus a higher recovery. Wettability alteration toward increased water wetness during LSWF is widely suggested as the cause of increased oil recovery. It has been determined experimentally that LSWF has a significant effect on the decrease in water relative permeability and increase in oil relative permeability (Webb et al. 2004; Rivet et al. 2010; Vledder et al. 2010; Morrow 2011; Fjelde et al. 2012).

The wettability shift from oil-wet to water-wet based on the polar molecules present in the crude oil and clay is explained by Seccombe et al. (2008) as follows. First the adsorption of these specific crude oil components onto reservoir rock makes the rock partly oil-wet. Oil is then desorbed from the clay surfaces by the injected low-salinity water causing wettability to change from oil-wet to waterwet. Hadia et al. (2011) performed experiments on two neutral-wet cores that showed no additional oil recovery due to LSWF. This observation may have some intuitive appeal in that the wetting state to begin with is already favorable. Sorbie and Collins (2010) stated that LSWF has little effect on systems that are already strongly water-wet because the system can no longer become more water-wet than it already is. Based on experiments performed by Spildo et al. (2012) and Alotaibi et al. (2011), intermediate-wet systems are considered as more favorable than water-wet systems. However, contrary to the majority observations, Sandengen et al. (2011) conducted core floods on a sandstone and reported that LSWF actually halted oil production, which the authors attributed to the shift in wettability to more oilwet conditions. Fjelde et al. (2012) also reported somewhat similar results in that the wettability of the system shifted from water-wet in high salinity floods to mixed-wet in the low-salinity floods. Both Sandengen et al. (2011) and Fjelde et al. (2012) explain the wettability shift based on the ion exchange occurring at the clay surface. Ashraf et al. (2010) carried out corefloods on Berea sandstone systems having four different types of wetting states, namely water-wet, neutral-wet, neutral-wet toward oil-wet and oil-wet. They concluded that the highest reduction in residual oil saturation by LSWF occurred at water-wet conditions, whereas the neutral-wet conditions result in the highest ultimate oil recovery. Based on the in-house experimental work on corefloods in which they used low-salinity water (referred to as 
designer water by Shell), Ligthelm et al. (2009) concludes that in sandstones the wettability alteration toward water-wet state by LSWF may be mostly due to the expansion of the electrical double layer and partly due to cation exchange processes. Other authors such as Mahzari and Sohrabi (2014) and Kasmaei and Rao (2015) conducted coreflooding experiments that focused on the variables/effects such as the formation of micro-dispersions when low-salinity water comes in contact with crude oil (depending on the surface active components present), sulfate concentration and temperature, which are listed as other reasons for the wettability shift. Nevertheless, all the reviewed literature does indicate one common trend and that is a shift in wettability due to LSWF.

\section{Continuous low-salinity injection vs. slug-wise injection}

Continuous low-salinity waterflooding is the optimum method for producing the highest recovery factor. However, slug-wise injections produce similar results and require much less freshwater. Seccombe et al. (2008) found that the most effective and economical method, from core injection analysis, is a slug-wise injection of $40 \%$ of the pore volume $(\mathrm{PV})$ and even state that project economics are significantly enhanced by injecting a slug of low-salinity water, which can be chased by high salinity water, rather than continuous injection. However, the determination of the optimum size of the slug as important, e.g., a 10\% PV slug showed no additional recovery and $30 \% \mathrm{PV}$, was the smallest slug necessary to flow through the entire core plug. Vledder et al. (2010) reported an incremental oil recovery of $10 \%$ to $15 \%$ due to a 40\% PV low-salinity injection in the Omar field in Syria. Kulathu et al. (2013) observed that residual oil saturation is achieved as early as 3-4 PV of injected low-salinity water with cyclic injection as compared to 6-7 PV's in continuous injection.

LSWF in the secondary mode refers to the injection of low-salinity water at the irreducible water saturation $\left(S_{\mathrm{wi}}\right)$, whereas LSWF in the tertiary mode means injection of low-salinity water after high salinity brine. Most of the experimental work in this area show increase in oil recovery in both modes (Zhang et al. 2007; Agbalaka et al. 2009). However, in some other studies, LSWF did not show any incremental oil recovery in tertiary mode (Rivet et al. 2010; Nasralla and Nasr-El-Din 2011).

\section{Grouping of possible low-salinity mechanisms}

There are various macroscopic and microscopic mechanisms for low-salinity waterflooding in the literature and still the exact mechanism is unknown. Boussour et al. (2009) analyzed possible mechanisms for LSWF and presented experimental counter-examples for most of them, including the presence of kaolinite, divalent ions in injected brine and the effect of temperature. However, there are a number of publications that support these mechanisms and are presented in the literature as follows:

(a) The increase in cation valency of a brine solution, which can be achieved with decrease in brine salinity, impacts increased oil recovery (Salathiel 1973).

(b) The first explanation for LSWF effects was from migration of fines (Tang and Morrow 1999; Zhang et al. 2007).

(c) The detachment of mixed-wet clay particles from the pore walls (Tang and Morrow 1997). Also with the use of low-salinity brine the fine materials become mobile which results in exposure of underlying rock surfaces and increases water wetness of the system (Tang and Morrow 1999).

(d) The increase in $\mathrm{pH}$ has been proposed as a driving mechanism in LSWF by a saponification mechanism of elevated $\mathrm{pH}$, the mineral surface exchange of $\mathrm{H}^{+}$in the liquid with cations and dissolution of carbonates (McGuire et al. 2005; Zhang et al. 2007; Lager et al. 2008a, b).

(e) Mechanism based on forces and molecular interaction between charged surfaces separated by liquid (Adamson and Gast 2007).

(f) Detachment of clay particles, cation exchange capacity (CEC) between clay minerals and invading brine has an improved effect in oil recovery with low-salinity water (Lager et al. 2008a, b).

(g) Multi-component ionic exchange (MIE) between mineral surfaces and invading brine is proved to be the primary mechanism underlying the improved recovery with low-salinity waterflood. It explains the importance of the presence of clay minerals and its cation exchange capacity with low-salinity water (Lager et al. 2008a, b; Omekeh et al. 2012).

(h) The salting-in effect (increase in solubility of polar organic molecules in brine by removing salt) has been suggested as it contributes to desorption of some organic materials loosely bonded to the clay surface (Rezaeidoust et al. 2009; Austad et al. 2010).

(i) Electric double-layer expansion is proved to be the primary mechanism in LSWF as it changes the electrical 
charge at both oil/brine and rock/brine interfaces to a highly negative charge which causes a repulsion force between the interfaces and changes wettability (Lee et al. 2010; Ramez and Nasr-El-Din 2014).

(j) Hamouda et al. (2014) observed from the experiments that for chalk formations, a possible mechanism was the presence of cations which alters wettability and for sandstone rocks, MIE, mineral dissolution and rock weakening causing fines migration.

The various mechanisms outlined above basically explain the different causes of wettability alteration toward a more favorable state resulting in the incremental recovery of oil when low-salinity water is injected.

\section{Contradictions or similarities between laboratory experiments and field evidence}

Numerous experiments have been conducted on LSWF on a core scale; however, the number of field tests is considerably less. Many of the reviewed papers indicate that field-wide benefits are slightly lower than laboratory studies. Robertson (2007) provided anecdotal evidence, through historic records, that field-wide LSWF can be a successful EOR method by analyzing the injection history of several waterfloods in the Powder River Basin, Wyoming. His results indicate that oil recovery increased as the salinity ratio of injected water decreased.

Increased oil recovery by LSWF in the near wellbore environment was demonstrated through log-inject-log tests by Webb et al. (2004). SWCTT has also been used to evaluate whether LSWF results from the field represent laboratory results. SWCTTs have been completed in the Prudhoe Bay's Borealis Field to determine the effectiveness of LSWF. The thickness in the test well is $20 \mathrm{ft}$ and has an average porosity of $16 \%$. Measured $S_{\text {or }}$ prior to LSWF was $0.21 \pm 0.02$ and measured $S_{\text {or }}$ after LSWF was $0.13 \pm 0.02$. The tests resulted in an additional $8 \% \mathrm{PV}$ of oil displacement due to LSWF (McGuire et al. 2005).

Seccombe et al. (2010) in their paper demonstrated the functionality of LSWF, as it does in corefloods and singlewell tests, in Endicott field interwell tests with one injector and one producer spaced $1000 \mathrm{ft}$ apart. They presented a straight-line fit of additional recovery due to LSWF vs. clay content, and based on the $12 \%$ clay content in the pilot area, an estimate of $13 \%$ additional recovery was made from this fit, which correlated quite well with the additional oil recovery of $\sim 10 \%$. This actually measured additional recovery was in response to the 11 months of $1.6 \mathrm{PV}$ low-salinity water injection. An extrapolation of the observed additional recovery of $10 \%$ and comparison with the scaled core floods indicated that the pilot is on track to achieve the original estimate of $13 \%$.

In the Omar field tests, and concurrent experiments, it was noted that the laboratory model showed additional recoveries within the range of what they expected and observed in the field tests. High salinity water injection was performed, and the recovery factors were recorded. Analogue fields were tested and the ultimate recovery factor for those fields was also recorded. A field-wide increase in the ultimate recovery factor of 5\%-15\% was observed. Laboratory tests modeling the waterflood showed a range of 9\%-23\% additional recovery. The data show a range of overlap of expected results, indicating that laboratory models could help achieve an estimation of how the waterflood will perform on a field-wide scale (Vledder et al. 2010).

There also exist examples of no benefit being realized from low-salinity floods. Skrettingland et al. (2011) conducted both laboratory and field tests to investigate the effectiveness of LSWF for the Upper Statfjord Formation in the Snorre Field. First they reported a marginal 2\% additional recovery based on the core floods conducted using LSWF, which perhaps was the motivation to conduct the SWCTT. The SWCTT, however, did not reveal any significant change in the remaining oil saturation. This leads them to conclude that the initial wetting state in the Snorre Field is already close to optimal for a seawater injection, thereby precluding the need for LSWF. Thus, the initial wetting conditions need to be considered in designing a LSWF, since it is a crucial property of the system that influences the outcome.

\section{Compositional variations in tested low-salinity waters}

The importance of clays and (modifying) the injection brine chemistry, which are factors that govern the LSWF response, was highlighted by Lee et al. (2010). The authors state that, specifically, the positive low-salinity response is attributed to increased clay content and lower divalent cation concentrations in the injection brine compared to connate brine. Cissokho et al. (2010) also reported that additional recovery due to LSWF occurred when there were no divalent ions present in the low-salinity brine.

Vaidya and Fogler (1992) give evidence of fines migration and formation damage due to changes in water composition. They found that in a system having exchangeable cations, the salinity and $\mathrm{pH}$ of the medium have some correlation and observed that for a $\mathrm{pH}$ value of 2.0 there is no effect on permeability but as $\mathrm{pH}$ increases there is a slight variation in permeability and at a value of $\mathrm{pH}$ greater than 11.0 there is a rapid and drastic decrease in permeability. Similarly, it is found that $\mathrm{pH}$ of permeating fluid increases as salinity decreases (Vaidya and Fogler 1992). 
Evidence that injected low-salinity water should be optimized to achieve the maximum benefit of LSWF was presented by Lager et al. (2008a, b). Only when the water was "optimized" did the reservoir improvement of 6\%-12\% recovery occur. They propose that it is important to model salinity changes within the reservoir to keep the salinity at an optimum level for maximum recovery.

Omekeh et al. (2012) studied the effect of carbonate minerals on the ion exchange process in low-salinity waterflooding and developed a model that describes multi-component ion exchange and the dissolution of carbonates contained within sandstones. They concluded through their analysis that the potential of low-salinity recovery is impacted because of dissolution of carbonate minerals, thus changing the composition of the injected low-salinity water and the concentration of the divalents on the rock surface.

Austad et al. (2010) proposed that the composition of the low-salinity injection water is of less importance, but that the formation water must contain active cations. The understanding of composition of formation water is more important in low-salinity waterflooding which contains divalent cations at low $\mathrm{pH}\left(\mathrm{e} . \mathrm{g}\right.$., $\left.\mathrm{Ca}^{2+}\right)$. Reaction of low-salinity water and this formation water causes desorption of organic material from clay. The water wetness of rock improves and hence increases oil recovery. The clay type/properties, its amount in rock, polar components in oil, the initial formation water composition and its $\mathrm{pH}$ are the important factors proposed in low-salinity mechanism.

Nasralla and Nasr-El-Din (2011) demonstrated that lowsalinity brines having low $\mathrm{Na}^{+}$resulted in a substantial reduction in the zeta potential at both the oil-brine and rock-brine interfaces, vis-à-vis highly negative charges. This is conducive to wettability alteration from oil-wet to water-wet and improvement in oil recovery. Similar results were reported by Wei et al. (2017). The cations in the injected water have more dominant effect on the recovery factor than water salinity (cation concentration), and the water chemistry is the dominant factor in determining the oil recovery factor, also highlighted by Lee et al. (2010). $\mathrm{NaCl}$ cation type showed the highest oil recovery over $\mathrm{CaCl}_{2}$ and $\mathrm{MgCl}_{2}$ (Nasralla and Nasr-El-Din 2011).

There is evidence that the generation of surfactants from residual oil at high $\mathrm{pH}$ may be the cause of the low-salinity recovery mechanism, and this can be accomplished by eliminating high concentration chemicals found in high salinity water. When injecting low-salinity water, the reaction of water and minerals from the reservoir takes place and hydroxyl ions are generated which increases the $\mathrm{pH}$ up to 9 or more. The compositional change of water reduces the interfacial tension between oil and water, it changes the properties of crude oil, and the elevated $\mathrm{pH}$ level generates surfactants which ultimately alter the surface tension (Webb et al. 2004; McGuire et al. 2005; Mahzari and Sohrabi 2014).

\section{Review of low-salinity waterflooding in carbonates}

According to the World Energy Outlook, more than $60 \%$ of the world's oil reserves are contained in carbonates, which are sedimentary rocks formed of minerals such as calcite and dolomite (Myint and Firoozabadi 2015), but are generally deficient in clay and certain other minerals (Lager et al. 2008a, b; RezaeiDoust et al. 2009). Therefore, as far as the underlying mechanisms of low-salinity waterflooding are concerned, clays are not included. In a recent survey by Derkani et al. (2018), they categorized the LSWF mechanism according to intrinsic or given parameters such as reservoir characteristics and extrinsic factors such as the injection brine. These are summarized here and a brief screening criterion has been provided.

Formation waters in carbonate reservoirs tend to be relatively more saline compared to those in sandstones. Derkani et al. (2018) noted the importance of formation water composition from the standpoint of reservoir souring and plugging when designing LSWF. As far as initial water saturation $\left(S_{\mathrm{wi}}\right)$ is concerned, similar to sandstones, water wetness is directly proportional to water saturation in carbonates also. Although, some studies discussed by these authors indicate an improvement in oil recovery with increasing initial water saturation, no concrete evidence is available in terms of LSWF.

The acid number of crude oil appears to be an influencing parameter from the wetting effect standpoint and thus oil recovery. The acid number is defined as $\mathrm{mg}$ of $\mathrm{KOH}$ (potassium hydroxide) required to neutralize $1 \mathrm{~g}$ of crude oil (containing acid compounds), which is typically determined by a titration test. Standnes and Austad (2000) tested the imbibition performance of chalk core saturated with six different crude oils with acid numbers ranging from 0 to 1.73 and reported that oil recovery and water wetness is inversely proportional to the acid number. Crude oil with 0 acid number showed the fastest imbibition producing more than $70 \%$ OOIP, whereas the one with the highest acid number showed almost no recovery. Although, their tests did not include LSW, the results could be qualitatively extrapolated at least from the acid number standpoint to LSWF.

The effect of reservoir temperature comes through wettability and the acid number, the former increasing toward water wetness (Rao 1996), whereas the latter decreasing with increasing reservoir temperature (Shimoyama and Johns 1972), although a given higher reservoir temperature can be considered as favorable for LSWF.

Nasralla et al's (2018) comprehensive experimental program on two different rock types from the same reservoir that evaluated the effect of salinity indicated that the optimum brine concentration is not the same since it is dependent on 
rock mineralogy and properties. For example, the two rock types studied by these authors differed in the permeability range from $2-20 \mathrm{mD}$ to $20-1000 \mathrm{mD}$, whereas the porosities were in the same range of $12 \%-27 \%$. The secondary Amott test results showed the highest recovery factor, using 10 times diluted seawater, for the high permeability rock type in the range of $30-60 \mathrm{mD}$, whereas those belonging to permeability range of $6-9 \mathrm{mD}$ and $300-400 \mathrm{mD}$, i.e., two different rock types, showed nearly the same recovery. Although the authors studied the mineralogy of both rock types via CT scanning, XRD and SEM, no explicitly distinguishing parameters between the two rock types were reported, and overall the rocks were classified as limestone, due to the high amount of calcite. Besides the above studies, despite the importance of porosity and permeability being key rock properties of carbonates that affect the recovery, the lack of systematic studies in open literature precludes a discussion of their impact on LSWF.

From the perspectives of extrinsic parameters, obviously the ionic composition of the (low salinity) injection brine is one of the most important in carbonates as well. However, temperature has also been discussed as one of the influential parameters in carbonates (Derkani et al. 2018). Unlike sandstones, the literature suggests that for the most part LSWF tends to focus on dilution or modification of seawater, which contains possible potential determining ions $\mathrm{Ca}^{2+}$ and $\mathrm{SO}_{4}{ }^{2-}$, that impart favorable wetting characteristics improving the recovery (Derkani et al. 2018; Zhang and Austad 2006). Based on the various cases discussed by Derkani et al. (2018), two main points, that are beneficial for enhancing oil recovery from carbonates, emerge; the injection brine should contain $\mathrm{Ca}^{2+}$ and/or $\mathrm{Mg}^{2+}$ and $\mathrm{SO}_{4}{ }^{2-}$ and temperature above $70{ }^{\circ} \mathrm{C}$. The synthetic seawater cases discussed by Derkani et al. (2018) include oil recovery as a function of varying $\mathrm{SO}_{4}{ }^{2-}$ concentration between $0-4$ times present in the original seawater while keeping the $\mathrm{Ca}^{2+}$ constant and vice versa, with temperatures in the range of $70-130{ }^{\circ} \mathrm{C}$. Overall, purely from a dilution perspective, a wide range of 10-100 times has been reported; however, inconsistent results preclude definitive recommendation on optimum concentration (Derkani et al. 2018).

Finally, the vast amount of literature (mostly laboratory scale and a handful of field cases) demonstrates the applicability of low salinity to improve oil recovery in carbonates; however, the potential is largely dependent on the specificity of the crude oil-brine-rock system, barring some general favorable screening guidelines such as (1) low acid number of oil; (2) higher $S_{\mathrm{wi}}$; (3) higher (reservoir) temperature $\left(70+{ }^{\circ} \mathrm{C}\right)$; and (4) the injection water containing $\mathrm{Ca}^{2+}$ and/ or $\mathrm{Mg}^{2+}$ and $\mathrm{SO}_{4}{ }^{2-}$.

\section{Enhancing polymer flooding by using low-salinity water}

Polymer flooding is a time honored and tested chemical EOR technique that has been successfully applied primarily to achieve a favorable mobility ratio and thus improve the sweep efficiency in heavy oils. However, one of the main requirements to prepare the polymer solution is the makeup water, which can be seawater, aquifer or produced formation water (Unsal et al. 2018). Each of these waters possess different salinities and when they are used to prepare solutions of widely employed polymers such as the partially hydrolyzed polyacrylamide (HPAM), the resulting rheological properties are strongly dependent on the salinity of the aqueous phase given their "polyelectrolyte character" (Nasr-El-Din and Taylor 1996; Venkatraman et al. 2014; Khorsandi et al. 2017; Unsal et al. 2018). According to Wever et al. (2011), the salinity of the aqueous phase is inversely proportional to viscosity of the polymer solution, which is the primary property targeted to improve the mobility ratio. In other words, if a certain polymer solution viscosity is desired then a lower concentration of polymer is needed if the solution is prepared in low-salinity water, compared to a higher concentration in high salinity water, which is typical in seawater and formation water. Vermolen et al. (2014) showed the effect of salinity on HPAM solution viscosity, for example, a $1000 \mathrm{ppm}$ and $10,000 \mathrm{ppm}$ total dissolved solids (TDS) salinity brines resulted in viscosities of $\sim 60 \mathrm{cP}$ and $\sim 20 \mathrm{cP}$ at a shear rate of $6 \mathrm{~s}^{-1}$. Other data presented by the same authors show similar examples such as a $100 \mathrm{cP}$ viscosity HPAM solution at a shear rate of $11.5 \mathrm{~s}^{-1}$ produced by mixing 2000 ppm HPAM in a $700 \mathrm{ppm}$ TDS brine vs. a 4000 ppm of HPAM in 7000 ppm TDS brine, which they refer to as "gain in polymer concentration." Clearly, this means that the low-salinity water use can lead to a substantial reduction in the amount of polymer required and thus making the entire operation economically attractive ranging from smaller injection facilities to ease of handling the (lower) concentration of polymer in the effluent stream (Unsal et al. 2018).

Besides the lower concentration advantage in using lowsalinity water, two other benefits are realized which are lower shear sensitivity and positive impact on the viscoelasticity of the polymer (Zaitoun et al. 2012; Vermolen et al. 2014). The polymer is susceptible to mechanical shearing in the flow infrastructure such as pumps, valves and chokes that result in the loss of viscosity because of the molecular weight decrease. Zaitoun et al. (2012) showed that the shear sensitivity decreases with decreasing water salinity, thus improving the stability of the HPAM. As far as viscoelasticity is concerned, it has been suggested that a higher value can reduce the residual oil saturation (Xia et al. 2008). 
Viscoelasticity increases with polymer concentration and molecular weight; however, salinity has a stronger influence (Vermolen et al. 2014).

Oil recovery and differential pressure data from an oil displacement experiment conducted by Vermolen et al. (2014) demonstrate the benefits of low-salinity polymer injection. First the same $100 \mathrm{cP}$ polymer solution viscosity is achieved with a $1000 \mathrm{ppm}$ and $250 \mathrm{ppm}$ TDS brine, which shows oil recoveries of $72 \%$ and a little over $80 \%$, respectively, demonstrating the improvement in not only the polymer economics (lower concentration of polymer), but also the lower salinity and/or a viscoelastic effect (a constant or decreasing differential pressure) (Vermolen et al. 2014). Coreflooding experiments conducted by Shiran and Skauge (2013) in a secondary mode showed an increase in the oil recovery factor when low salinity, $300 \mathrm{ppm}$ polymer and low-salinity polymer were injected. Recently, Al-Qattan et al. (2018) reported single-well chemical tracer tests conducted in one of the producers in the Wara reservoir of the Greater Burgan Field in Kuwait that show the efficacy of a low-salinity waterflood followed by low-salinity polymer flood in a tertiary mode post the high salinity waterflood that reduced the residual oil saturation by $3 \%$ and $4 \%$ due to the two low-salinity floods. Nevertheless, the reduction in residual oil saturation is attributed to a combination of the higher viscosity effect due to polymer and low salinity producing favorable wetting conditions; however, the dominant mechanism is dependent on the reservoir characteristics (Unsal et al. 2018).

\section{Conclusions}

There is no universally applicable primary mechanism behind low-salinity waterflooding known as yet; however, wettability alteration due to $\mathrm{pH}$ alteration and salinity changes and electric double-layer expansion/MIE are widely discussed mechanisms in the literature. Commonly researched topics, as they relate to LSWF, include presence of clay, wettability and water chemistry. Reservoirs that are mixed-wet have shown to be more attractive candidates for LSWF. Optimum injected water salinity will depend on the composition of the reservoir brine, and LSWF benefits have been the highest in injection water salinity ranging between $2000 \mathrm{ppm}$ and $5000 \mathrm{ppm}$ TDS. Slug-wise injection of lowsalinity water has also been suggested to enhance the project economics.

Clay type is one of the most discussed topics in published works referencing LSWF. Some have proposed that kaolinite would be the least favorable clay, but many positive results have come from sandstones containing kaolinite. Many experiments have been conducted with kaolinite clays, but
Table 3 Preliminary proposed screening criteria

\begin{tabular}{lll}
\hline Variable & Favorable & Unfavorable \\
\hline Clay present & Yes & No \\
Clay content & High & Low \\
Salinity of brine & $2000-5000 \mathrm{ppm}$ & $>7000 \mathrm{ppm}$ \\
pH of the medium & $>7$ & $<7$ \\
Oil composition & Polar components & Non-polar components \\
Wettability & Strongly oil-wet & Strongly water-wet \\
Connate water & Brackish (Yes) & Fresh (No) \\
Formation type & Sandstone & Carbonate \\
EOR mode & Secondary & Tertiary \\
\hline
\end{tabular}

little with other clays. A comprehensive study comparing the clay type and amount of clay could provide evidence into the optimum clay characteristics amenable to LSWF.

Two other observations from the literature review are: (1) Laboratory and field experiments generally seem to match each other, though field-wide benefits are slightly lower than laboratory studies and (2) there is a lack of study relating oil properties (such as API gravity and viscosity) and rock properties (such as porosity, pore size and permeability) to the benefits of LSWF.

There are several factors to consider when selecting reservoir candidates for LSWF. A preliminary screening criterion is proposed, as shown in Table 3. Despite the different explanations of how LSWF mechanism works and the many parameters that play a role, there seems to be some common features in LSWF, which are:

1. Clays should be present and clay content must be high.

2. Formation water and/or seawater (high salinity) from prior flooding have to be present.

3. The salinity of the low-salinity injected brine should be below the optimum salinity, i.e., TDS $<5000 \mathrm{ppm}$.

4. A polar component has to be present in oil.

5. The reservoir has to be oil-wet or mixed-wet (or intermediate-wet)

A sensitivity study of each parameter will help to better identify which mechanisms contribute the most to the benefits of LSWF. LSWF response is unique to each reservoir; therefore, careful planning and understanding, on a case by case basis, is necessary in order to determine the potential of LSWF for field-wide implementation.

LSWF in carbonates is mainly tied to diluted seawater. Low acid number, higher temperatures and the presence of $\mathrm{Ca}^{2+}$ and/or $\mathrm{Mg}^{2+}$ and $\mathrm{SO}_{4}{ }^{2-}$ appear to some of the mechanistically favorable factors for low LSWF in carbonates. Unlike sandstones, clays do not seem to play a major role in LSWF in carbonates. 
The reviewed literature demonstrates the synergy between the LSWF and polymer flooding that helps in further reduction in the residual oil saturation.

Open Access This article is distributed under the terms of the Creative Commons Attribution 4.0 International License (http://creativeco mmons.org/licenses/by/4.0/), which permits unrestricted use, distribution, and reproduction in any medium, provided you give appropriate credit to the original author(s) and the source, provide a link to the Creative Commons license, and indicate if changes were made.

\section{References}

Adamson AW, Gast AP. Physical chemistry of surfaces. 6th ed. New York: Wiley; 2007.

Agbalaka CC, Dandekar AY, Patil SL, Khataniar S, Hemsath JR. Coreflooding studies to evaluate the impact of salinity and wettability on oil recovery efficiency. Transp. Porous Media. 2009;76(1):7794. https://doi.org/10.1007/s11242-008-9235-7.

Agbalaka C. Review and experimental studies to evaluate the impact of salinity and wettability on oil recovery efficiency. MS Thesis, University of Alaska Fairbanks, May 2006.

Aladasani A, Bai B, Wu YS. Investigating low-salinity waterflooding recovery mechanisms in sandstone reservoirs. In: The eighteenth SPE improved oil recovery symposium, Tulsa, Oklahoma, 14-18 April 2012. https://doi.org/10.2118/152997-MS.

Alotaibi MB, Nasralla RA, Naser-El-Din HA. Wettability studies using low-salinity water in sandstone reservoirs. SPE Reserv. Eval. Eng. 2011;14(6):713-25. https://doi.org/10.2118/149942-PA.

Al-Qattan A, Sanaseeri A, Al-Saleh Z, Singh BB, Al-Kaaoud H, Delshad $\mathrm{M}$, et al. Low salinity waterflood and low salinity polymer injection in the Wara Reservoir of the Greater Burgan Field. In: SPE EOR conference at oil and gas West Asia, 26-28 March, Muscat, Oman, 2018. https://doi.org/10.2118/190481-MS.

Ashraf A, Hadia N, Torsater N, Tweheyo M. Laboratory investigation of low salinity waterflooding as secondary recovery process: effect of wettability. In: SPE oil and gas india conference and exhibition, Mumbai, India, 20-22 January 2010. https://doi. org/10.2118/129012-MS.

Austad T, RezaeiDoust A, Puntervold T. Chemical mechanism of low salinity water flooding in sandstone reservoirs. In: SPE improved oil recovery symposium, Tulsa, Oklahoma, 24-28 April, 2010. https://doi.org/10.2118/129767-MS.

Berg S, Cense AW, Jansen E, Bakker K. Direct experimental evidence of wettability modification by low salinity. In: International symposium of the society of core analysts, Noordwijk aan Zee, Netherlands, 27-30 September 2009.

Bernard GG. Effect of floodwater salinity on recovery of oil from cores containing clays. In: Thirty-eight annual california regional meeting of SPE, Los Angeles, California, 26-27 October; 1967. https ://doi.org/10.2118/1725-MS.

Boussour S, Cissokho M, Cordier P, Bertin H, Hamon G. Oil recovery by low salinity brine injection: Laboratory results on outcrop and reservoir cores. In: SPE annual technical conference and exhibition, New Orleans, Louisiana, 4-7 October 2009. https://doi. org/10.2118/124277-MS.

British Petroleum. "Less Salt More Oil," August 2009, Frontiers magazine article, pp. 6-9, 2009.

Buckley JS, Liu Y, Monsterleet S. Mechanism of wetting alteration by crude oils. In: SPE international symposium on oilfield chemistry, Houston, Texas, 18-21 February 1998. https://doi. org/10.2118/37230
Cissokho M, Boussour S, Cordier P, Bertin H, Hamon G. Low salinity oil recovery on clayey sandstone: experimental study. In: International symposium of the society of core analysts, Noordwijk aan Zee, Netherlands, 27-30 September, 2010.

Dang CTQ, Nghiem LX, Chen Z, Nguyen QP, Nguyen NTB. State-ofthe art low salinity waterflooding for enhanced oil recovery In: SPE Asia Pacific oil and gas exhibition, Jakarta, Indonesia, 22-24 October; 2013a. https://doi.org/10.2118/165903-MS.

Dang CTQ, Nghiem LX, Chen Z, Nguyen QP. Modelling low salinity waterflooding: ion exchange, geochemistry and wettability alteration. In: SPE annual technical conference and exhibition held in New Orleans, Louisiana, 30 September-2 October; 2013b. https ://doi.org/10.2118/166447-MS.

Derkani MH, Fletcher AJ, Abdallah W, Sauerer B, Anderson J, Zhang ZJ. Low salinity waterflooding in carbonate reservoirs: review of interfacial mechanisms. Colloids Interfaces. 2018;2:20. https:// doi.org/10.3390/colloids2020020.

Fjelde I, Asen SM, Omekeh A. Low salinity waterflooding experiments and interpretation by simulations. In: The eighteenth SPE improved oil recovery symposium, Tulsa, Oklahoma, 14-18 April 2012. https://doi.org/10.2118/154142-MS.

Fjelde I, Omekeh AV, Sokama-Neuyam YA. Low salinity waterflooding: effect of crude oil composition. In: SPE improved oil recovery symposium, Tulsa, Oklahoma, 12-16 April 2014. https://doi. org/10.2118/169090-MS.

Gamage P, Thyne G. Comparison of oil recovery by low salinity waterflooding in secondary and tertiary recovery modes. In: SPE annual technical conference and exhibition, Denver, Colorado, 30 October-2 November 2011. https://doi.org/10.2118/147375-MS.

Hadia N, Kumar KG, Torsaeter O. Laboratory investigation of low salinity waterflooding on reservoir rock samples from the Frøy field. In: SPE middle east oil and gas show and conference, Manama, Bahrain, 25-28 September, 2011. https://doi. org/10.2118/14114-MS.

Hamouda AA, Valderhaug OM, Munaev R, Stangeland H. Possible mechanisms for oil recovery from chalk and sandstone rocks by low salinity water (LSW). In: SPE improved oil recovery symposium, Tulsa, Oklahoma, 12-16 April 2014 https://doi. org/10.2118/169885-MS.

Hassenkam T, Matthiesen J, Pedersen CS, Stipp SLS, Collins IR. Observation of the low salinity effect by atomic force adhesion mapping on reservoir sandstone. In: The eighteenth SPE improved oil recovery symposium, Tulsa, Oklahoma, 14-18 April 2012. https://doi.org/10.2118/154037-MS.

Jerauld GR, Webb KG, Lin CY, Seccombe JC. Modeling low-salinity waterflooding. In: SPE annual technical conference and exhibition, San Antonio, Texas, 24-27 September, 2006. https://doi. org/10.2118/102239-MS

Kabay N, Kahveci H, Ipek O, Yuksel M. Separation of monovalent and divalent ions from ternary mixture by electrodialysis. In: Paper Elsevier 7365, presented at 2005 2nd membrane science and technology conference of Visegrad Countries (PERMEA), Polanica Zdroj, Poland, 18-22 September 2005.

Kasmaei AK, Rao DN. Is wettability alteration the main case for enhanced oil recovery in low salinity waterflooding. SPE Reserv. Eval. Eng. 2015;18(2):228-35. https://doi.org/10.2118/16912 0 -PA.

Khorsandi S, Qiao C, Johns RT. Displacement efficiency for low salinity polymer flooding including wettability alteration. SPE J. 2017;22(2):417-30. https://doi.org/10.2118/179695-PA.

Kristensen M, Ayan C, Ramamoorthy R, Cig K. Feasibility of an EOR MicroPilot for low-salinity water flooding. In: International petroleum technology conference, Bangkok, Thailand, 7-9 February 2011. Paper IPTC 14507.

Kulathu S, Dandekar AY, Patil S, Khataniar S. Low salinity cyclic waterfloods for enhanced oil recovery on Alaska North Slope. In: 
SPE Asia Pacific oil and gas conference and exhibition, Jakarta, Indonesia, 22-24 October 2013. https://doi.org/10.2118/16581 2-MS.

Lager A, Webb KJ, Collins IR, Richmond DM. LoSal ${ }^{\mathrm{TM}}$ enhanced oil recovery: evidence of enhanced oil recovery at the reservoir scale. In: SPE/DOE symposium on improved oil recovery, Tulsa, Oklahoma, 19-23 April, 2008a. https://doi.org/10.2118/113976-MS.

Lager A, Webb KJ, Black C, Singleton M, Sorbie KS. Low salinity oil recovery-an experimental investigation. Petrophysics. 2008b;49(1).

Lee SY, Webb KJ, Collins IR, Lager A, Clarke SM, O'Sullivan M, et al. Low salinity oil recovery: increasing understanding of the underlying mechanisms. In: SPE improved oil recovery symposium, Tulsa, Oklahoma, 24-28 April 2010. https://doi. org/10.2118/129722-MS.

Ligthelm DJ, Gronsveld J, Hofman JP, Brussee F, Marcelis F, van der Linde HA. Novel waterflooding strategy by manipulation of injection brine composition. In: SPE EUROPE/EDGE annual conference and exhibition, Amsterdam, Netherlands, 8-11 June 2009. https://doi.org/10.2118/119835-MS.

Loahardjo N, Xie X, Yin P, Morrow NR. Low salinity waterflooding of a reservoir rock. In: International symposium of the society of core analysts, Calgary, Canada, 10-12 September 2007. Paper SCA2007-29.

Mahzari P, Sohrabi M. Crude oil/brine interactions and spontaneous formation of micro-dispersions in low salinity water injection. In: SPE improved oil recovery symposium, Tulsa, Oklahoma, 12-16 April 2014. https://doi.org/10.2118/169081-MS.

McGuire PL, Chatham JR, Paskvan FK, Sommer DM, Carini FH. Low salinity oil recovery: an exciting new EOR opportunity for Alaska's North Slope. In: SPE western regional meeting, Irvine, California, 30th March-1st April, 2005. https://doi.org/10.2118/93903 -MS.

Morrow N. Improved oil recovery by waterflooding and spontaneous imbibition. In: EORI TAB Meeting, presentation. 2011.

Morrow N, Buckley J. Improved oil recovery by low-salinity waterflooding. J. Petrol. Technol. 2011;65(5):106-12. https://doi. org/10.2118/129421-PA.

Myint PC, Firoozabadi A. Thin liquid films in improved oil recovery from low-salinity brine. Colloid Interface Sci. 2015;20:105-14. https://doi.org/10.1016/j.cocis.2015.03.002.

Nasr-El-Din HA, Taylor KC. Rheology of water-soluble polymers used for improved oil recovery. Advances in engineering fluid mechanics: multiphase reactor and polymerization system hydrodynamics. Gulf Professional Publishing, 1996. Chapter 24, pp. 622-634.

Nasralla RA, Mahani H, van der Linde HA, Marcelis FH, Masalmeh SK, Sergienko E, Brussee NJ, Pieterse SG, Basu S. Low salinity waterflooding for a carbonate reservoir: experimental evaluation and numerical interpretation. J. Pet. Sci. Eng. 2018;164:640-54. https://doi.org/10.1016/j.petrol.2018.01.028.

Nasralla RA, Nasr-El-Din HA. Impact of electrical surface charges and cation exchange on oil recovery by low salinity water. In: SPE Asia Pacific oil and gas conference and exhibition, Jakarta, Indonesia, 20-22 September 2011. https://doi.org/10.2118/14793 7-MS.

Omekeh A, Friis HA, Fjelde I, Evje S. Modeling of ion-exchange and solubility in low salinity waterflooding. In: The eighteenth SPE improved oil recovery symposium, Tulsa, Oklahoma, 14-18 April 2012. https://doi.org/10.2118/154144-MS.

Patil S, Dandekar AY, Patil SL, Khataniar S. Low salinity brine injection for EOR on Alaska North Slope (ANS). In: International petroleum technology conference, Kuala Lumpur, Malaysia, 3-5 December, 2008. https://doi.org/10.2523/IPTC-12004-MS.

$\mathrm{Pu} \mathrm{H}$, Xie X, Yin P, Morrow NR. Low salinity waterflooding and mineral dissolution. In: SPE annual technical conference and exhibition, Florence, Italy, 19-22 September, 2010. https://doi. org/10.2118/134042-MS

Ramez AN, Nasr-El-Din HA. Impact of electrical surface charges and cation exchange on oil recovery by low salinity water. In: SPE Asia Pacific oil and gas conference and exhibition, Jakarta, Indonesia, 20-22 September, 2011. https://doi.org/10.2118/14793 7-MS.

Ramez AN, Nasr-El-Din HA. Double-layer expansion: Is it a primary mechanism of improved oil recovery by low salinity waterflooding? In: SPE improved oil recovery symposium, Tulsa, Oklahoma, 12-16 April, 2014. https://doi.org/10.2118/154334-MS.

Rao DN. Wettability effects in thermal recovery operations. In: SPE/ DOE improved oil recovery symposium, Tulsa, OK, 21-24 April 1996. https://doi.org/10.2118/35462-MS.

Reddick C, Buikema T, Williams D. Managing risk in the deployment of new technology-Getting LoSal ${ }^{\mathrm{TM}}$ EOR into the business. In: Eighteenth SPE improved oil recovery symposium, Tulsa, Oklahoma, 14-18 April 2012. https://doi.org/10.2118/153993-MS.

RezaeiDoust A, Puntervold T, Strand S, Austad T. Smart water as wettability modifier in carbonate and sandstone: a discussion of similarities/differences in chemical mechanism. Energy Fuels. 2009;23(9):4479-85. https://doi.org/10.1021/ef900185q.

Rivet SM, Lake LW, Pope GA. A coreflood investigation of low-salinity enhanced oil recovery. In: SPE annual technical conference and exhibition, Florence, Italy, 19-22 September, 2010. https:// doi.org/10.2118/134297-MS.

Robertson EP, Thomas CP, Zhang Y, Morrow NR. Improved waterflooding through injection brine modification. Idaho National Laboratory Report INEEL/EXT-02-01591, DOE Contract DE-AC07-99ID13727 (January 2003), 2003.

Robertson EP. Low-salinity waterflooding to improve oil recoveryHistorical field evidence. In: SPE annual technical conference and exhibition, November 2007. https://doi.org/10.2118/109965-MS.

Robertson EP. Oil recovery increases by low-salinity flooding: Minnelusa and Green River formations. In: SPE annual technical conference and exhibition, Florence, Italy, 19-22 September 2010. https://doi.org/10.2118/132154-MS.

Salathiel RA. Oil recovery by surface film drainage in mixed-wettability rocks. J. Petrol. Technol. 1973;25(10):1216-24. https://doi. org/10.2118/4104-PA.

Sandengen K, Tweheyo MT, Raphaug M, Kjolhamar A, Crescente C, Kippe V. Experimental evidence of low salinity waterflooding yielding a more oil-wet behavior. In: The international symposium of the society of core analysts, Austin, Texas, 18-21 September, 2011. Paper SCA2011-16.

Seccombe JC, Lager A, Webb K, Jerauld G, Fueg E. Improving waterflood recovery: LoSal ${ }^{\mathrm{TM}}$ EOR field evaluation. In: SPE/DOC improved oil recovery symposium, Tulsa, Oklahoma, 19-23 April 2008. https://doi.org/10.2118/113480-MS.

Seccombe JC, Lager A, Jerauld G, Jhaveri B, Buikema T, Bassler $S$, et al. Demonstration of low-salinity EOR at interwell Scale, Endicott Field, Alaska. In: SPE improved oil recovery symposium, Tulsa, Oklahoma, 24-28 April 2010. https://doi. org/10.2118/129692-MS.

Shimoyama A, Johns WD. Formation of alkanes from fatty acids in the presence of $\mathrm{CaCO}_{3}$. Geochim. Cosmochim. Acta. 1972;36:87-91. https://doi.org/10.1016/0016-7037(72)90122-6.

Shiran BS, Skauge A. Wettability and oil recovery by low salinity injection. In: SPE EOR conference at oil and gas West Asia, Muscat, Oman, 16-18 April 2012. https://doi.org/10.2118/15565 1-MS.

Shiran BS, Skauge A. Enhanced oil recovery (EOR) by combined low salinity water/polymer flooding. Energy Fuels. 2013;27:1223-35. https://doi.org/10.1021/ef301538e.

Skrettingland K, Holt T, Tweheyo MT, Skjevrak I. Snorre low-salinity water injection-coreflooding experiments and single-well field 
pilot. SPE Reserv. Eval. Eng. 2011;14(2):182-92. https://doi. org/10.2118/129877-PA.

Sorbie KS, Collins IR. A proposed pore-scale mechanism for how low salinity waterflooding works. In: SPE improved oil recovery symposium, Tulsa, Oklahoma, 24-28 April 2010. https://doi. org/10.2118/129833-MS.

Spildo K, Johannessen AM, Skauge A. Low salinity waterflood at reduced capillarity. In: The eighteenth SPE improved oil recovery symposium, Tulsa, Oklahoma, 14-18 April 2012. https://doi. org/10.2118/154236-MS.

Standnes DC, Austad T. Wettability alteration in chalk: 1 Preparation of core material and oil properties. J Pet Sci Eng. 2000;28:111-21. https://doi.org/10.1016/S0920-4105(00)00083-8.

Suijkerbuijk B, Hofman J, Ligthelm DJ, Romanuka J, Brussee N, van der Linde $\mathrm{H}$, et al. Fundamental investigations into wettability and low salinity flooding by parameter isolation. In: The eighteenth SPE improved oil recovery symposium, Tulsa, Oklahoma, 14-18 April, 2012. https://doi.org/10.2118/154204-MS.

Tang GQ, Morrow NR. Salinity, temperature, oil composition, and oil recovery by waterflooding. In: SPE annual technical conference and exhibition, Denver, Colorado, 6-9 October, 1997. https://doi. org/10.2118/36680-MS

Tang GQ, Morrow NR. Influence of brine composition and fines migration on crude oil/brine/rock interactions and oil recovery. J. Petrol. Sci. Eng. 1999;24(2-4):99-110. https://doi.org/10.1016/S0920 $-4105(99) 00034-0$.

Tchistiakov A. Colloid chemistry of in situ clay-induced formation damage. In: SPE international symposium on formation damage control, Lafayette, Louisiana, 23-24 February, 2000. https://doi. org/10.2118/58747-MS.

Thyne G, Gamage P. Evaluation of the effect of low salinity waterflooding for 26 fields in wyoming. In: SPE annual technical conference and exhibition, Denver, Colorado, 30th October-2 November, 2011. https://doi.org/10.2118/147410-MS.

Unsal E, ten Berge ABGM, Wever DAZ. Low salinity polymer flooding: lower polymer retention and improved injectivity. J. Petrol. Sci. Eng. 2018;163:671-82. https://doi.org/10.1016/j.petro 1.2017.10.069.

Vaidya RN, Fogler HS. Fines migration and formation damage: influence of $\mathrm{pH}$ and ion exchange. SPE Prod. Eng. 1992;7(4):325-30. https://doi.org/10.2118/19413-PA.

Venkatraman A, Hesse MA, Lake LW, Johns RT. Analytical solutions for flow in porous media with multicomponent cation exchange reactions. Water Resour. Res. 2014;50(7):5831-47. https://doi. org/10.1002/2013WR015091.

Vermolen ECM, Pingo Almada M, Wassing BM, Lighthelm DJ, Shehadah M. Low-salinity polymer flooding: improving polymer flooding technical feasibility and economics by using low-salinity make-up brine. In: International petroleum technology conference, 19-22 January, Doha, Qatar; 2014. https://doi.org/10.2523/ IPTC-17342-MS.
Vledder P, Gonzalez IE, Carrera Fonseca JC, Wells T, Ligthelm DJ. Low salinity water flooding: proof of wettability alteration on a field wide scale. In: SPE improved recovery symposium, Tulsa, Oklahoma, 24-28 April, 2010. https://doi.org/10.2118/12956 4-MS.

Webb KJ, Black CJJ, Al-Ajeel H. Low salinity oil recoveryLog-Inject-Log. In: SPE/DOE symposium on improved oil recovery, Tulsa, Oklahoma, 17-21 April 2004. https://doi. org/10.2118/89379-MS.

Wei B, Lu L, Li Q, Li H, Ning X. Mechanistic study of oil/brine/ solid interfacial behaviors during low-salinity waterflooding using visual and quantitative methods. Energy Fuels. 2017;31:6615-24. https://doi.org/10.1021/acs.energyfuels.7b00825.

Wever DAZ, Picchioni F, Broekhuis AA. Polymers for enhanced oil recovery: a paradigm in structure-property relationship. Prog. Polym. Sci. 2011;36(11):1558-628. https://doi.org/10.1016/j. progpolymsci.2011.05.006.

Xia HF, Wang DM, Wang G, Ma WG, Liu J. Mechanism of the effect of micro-forces on residual oil saturation in chemical flooding. SPE symposium on improved oil recovery, 20-23 April, Tulsa, Oklahoma, USA. 2008. https://doi.org/10.2118/114335-MS.

Yousef AA, Al-Saleh S, Al-Jawfi M. Improved/enhanced oil recovery from carbonate reservoirs by tuning injection water salinity and ionic content. In: SPE improved oil recovery symposium, Tulsa, Oklahoma, 14-18 April, 2012. https://doi.org/10.2118/15407 6-MS.

Zahid A, Shapiro A, Skauge A. Experimental studies of low salinity water flooding carbonate: A new promising approach. In: SPE EOR conference at oil and gas West Asia, Muscat, Oman, 16-18 April, 2012a. https://doi.org/10.2118/155625-MS.

Zahid A, Stenby EH, Shapiro AA. Smart waterflooding (High Sal/Low $\mathrm{Sal}$ ) in carbonate reservoirs. In: EAGE annual conference and exhibition incorporating SPE Europe, Copenhagen, Denmark, 4-7 June, 2012b. https://doi.org/10.2118/154508-MS.

Zaitoun A, Makakou P, Blin N, Al-Maamari RS, Al-Hashmi AAAR, Abdel-Goad M, et al. Shear stability of EOR polymers. SPE J. 2012;17(02):335-9. https://doi.org/10.2118/141113-PA.

Zhang Y, Xie X, Morrow NR. Waterflood performance by injection of brine with different salinity for reservoir cores. In: SPE annual technical conference and exhibition, Anaheim, CA, USA, 11-14 November 2007. https://doi.org/10.2118/109849-MS.

Zhang P, Austad T. Wettability and oil recovery from carbonates: effects of temperature and potential determining ions. Colloids Surf. A Physicochem. Eng. Asp. 2006;279:179-87. https://doi. org/10.1016/j.colsurfa.2006.01.009. 